\title{
An Experimental Study on the Basic Mechanical Properties and Compression Size Effect of Rubber Concrete with Different Substitution Rates
}

\author{
Yanli Hu, ${ }^{1,2}$ Xuewei Sun, ${ }^{1}$ Aiqun Ma, ${ }^{1}$ and Peiwei Gao $\mathbb{D D}^{1}$ \\ ${ }^{1}$ Department of Civil and Airport Engineering, Nanjing University of Aeronautics and Astronautics, Nanjing 210016, China \\ ${ }^{2}$ College of Civil Engineering, Yancheng Institute of Technology, Yancheng 224051, China
}

Correspondence should be addressed to Peiwei Gao; gpw1963@nuaa.edu.cn

Received 4 May 2020; Revised 27 August 2020; Accepted 15 October 2020; Published 16 November 2020

Academic Editor: Junhui Zhang

Copyright (c) 2020 Yanli $\mathrm{Hu}$ et al. This is an open access article distributed under the Creative Commons Attribution License, which permits unrestricted use, distribution, and reproduction in any medium, provided the original work is properly cited.

\begin{abstract}
An experimental study was carried out on the uniaxial compression, uniaxial splitting, pure shear, and compression size effect of rubber concrete with 5 different substitution rates by applying hydraulic servo and direct shear apparatus. Then, by comparing the failure modes and ultimate strength eigenvalues of rubber concrete under different loading conditions, the following conclusions were drawn: with the increase of rubber substitution rate, the concrete specimens maintain a relatively good integrity under uniaxial compressive failure; on the contrary, the failure sections under uniaxial slitting and pure shear gradually become uneven with an increasing amount of fallen rubber particles. With the increase of specimen size, the integrity of rubber concrete after failure is gradually improved. Affected by an increased rubber substitution rate, the uniaxial compressive strength, splitting tensile strength, and shear strength of the concrete gradually decrease, while the plastic deformation capacity gradually increases. Specifically, the compressive strength is reduced by a maximum of $60.67 \%$; the shear strength is reduced by a maximum of $49.85 \%$; and the uniaxial splitting strength is reduced by a maximum of $58.38 \%$. Then, we analyzed the strength relationship and the underlying mechanism among the three types of loading modes. It is found that, at the same rubber substitution rate, the compressive strength of rubber concrete gradually increases as the specimen size decreases, and the size effect on the compressive strength gradually decreases as the rubber substitution rate increases. Meanwhile, we performed qualitative and quantitative analysis on the equation describing the coupling effect of specimen size and rubber substitution rate on the compressive strength; the results suggest that the proposed equation is of a high level of applicability. Our research has a reference value for the application and promotion of rubber concrete in actual engineering projects.
\end{abstract}

\section{Introduction}

Rubber concrete refers to a new type of concrete that is formed by quantitatively substituting a part of fine aggregate or coarse aggregate with rubber particles. This new concrete is featured with high impact resistance, high crack resistance, and good toughness, for which it has drawn a wide concern from both domestic and foreign scholars. At the same time, the rubber particles that are currently used in rubber concrete mainly come from waste tires. This is of great significance for environmental protection. Therefore, the development and engineering applications of rubber concrete have shown a very promising prospect [1-3].
The existing research on rubber concrete basically concentrates on its mechanical properties, durability, and structural applications. Toutanji [4] studied the effects of the proportion of rubber particles and the particle size on the compressive strength of concrete and found that particle size had a greater effect on the concrete strength. Eldin and Senouci [5] investigated the performance of water-soaked rubber particles and reported that the strength of the rubber concrete containing water-soaked particles was increased by $16 \%$ compared with that of normal rubber concrete. Paine et al. [6] examined the antifreezing performance of rubber concrete and found that rubber concrete exhibited a better antifreezing performance. Bignozzi and Sandrolini [7] 
formulated self-compacting rubber concrete using rubber particles and studied its basic mechanical properties. Topçu [8] investigated the effect of different rubber particle sizes on the mechanical properties of concrete and showed that the larger the rubber particle size, the more significant the effect on the mechanical properties of concrete. Li et al. [9] used $\mathrm{NaOH}$ to treat rubber particles, and the results showed that the mechanical properties of the treated rubber concrete were significantly increased compared to the untreated conditions. Güneyisi et al. [10] added a certain amount of silicon powder to the rubber concrete, and the results showed silicon powder helps to reduce the rubber particle size and content to reduce the strength and elastic modulus of rubber concrete. Sallam et al. [11] conducted a drop hammer impact test on rubber concrete cylinders, and the results showed that the strength of rubber concrete gradually increased under the influence of the loading strain rate, while rubber concrete can have a better inhibitory effect on cracks. Atahan and Yücel [12] conducted impact tests on rubber concrete and the results showed that rubber concrete can absorb impact energy better, and rubber concrete has better impact resistance. Tian et al. [13] studied the splitting tensile strength and the corresponding failure mode of rubber concrete. Chen [14] analyzed how rubber particles slowed down the development of concrete cracks during the freeze-thaw cycle from a microscopic point of view. Meanwhile, Si et al. [15] applied sodium hydroxide to pretreat rubber particles in order to improve the concrete strength. Gonen [16] examined the dynamic properties of rubber concrete and reported that rubber concrete exhibited a good impact resistance. In the feasibility study on the actual complex concrete structures, it is usually necessary to conduct model experiment to investigate the mechanical properties of the concrete structure, but it is noteworthy that there may be a large difference between the model specimen size and the actual engineering size. In view of the significant size effect of concrete (i.e., the mechanical properties of concrete are affected by the size), a comprehensive study on the size effect will be helpful for analyzing the relationship between the actual concrete structure and the experiment model in terms of mechanical properties. With respect to ordinary concrete under compressive and tensile loading conditions, there has been a large amount of literature on the size effect from the perspectives of theoretical research and experimental analysis [17-19]. The research on the basic mechanical properties and size effect of rubber concrete can help us further promote the applications of rubber concrete in engineering practice. However, to the best of the authors' knowledge, no research has been reported yet on the shear mechanical properties and size effect of rubber concrete.

In this paper, we conducted experimental research on the basic mechanical properties (i.e., compressive, splitting, and pure shear) and compression size effect of rubber concrete with consideration of 5 different rubber substitution rates $(0 \%, 10 \%, 20 \%, 30 \%$, and $40 \%)$. By comparing the failure modes and ultimate strength eigenvalues of rubber concrete under different loading conditions, we analyzed the influence of different rubber substitution rates on the basic mechanical properties and compression size effect of rubber concrete from both qualitative and quantitative perspectives and further discussed the underlying mechanisms in detail.

\section{Experiment Plan}

2.1. Specimen Design and Mix Proportion. The experimental study on the basic mechanical properties (compression, uniaxial tension, and pure shear) and the compression size effect of rubber concrete based on 5 different rubber particle substitution rates $(0 \%, 10 \%, 20 \%, 30 \%$, and $40 \%)$ was conducted. The concrete specimen containing $0 \%$ rubber was taken as the reference (ordinary concrete). The designed strength of the reference concrete is $30 \mathrm{MPa}$. The concrete mix proportion was determined by referring to the "Specification for Mix Proportion Design of Ordinary Concrete" JGJ55-2011. For the preparation of rubber concrete specimens with different substitution rates, the water, cement (ordinary Portland cement P.O 42.5), and coarse aggregate (gravels with a particle size ranging from 4 to $16 \mathrm{~mm}$ ) used were from the same sources. The rubber particle size range is $2 \sim 5 \mathrm{~mm}$, the apparent density is $1270 \mathrm{~kg} / \mathrm{m}^{3}$, the bulk density is $820 \mathrm{~kg} / \mathrm{m}^{3}$, the fiber content is not more than $0.1 \%$, the tensile strength is not less than $15 \mathrm{MPa}$, and the elongation at break is not less than $500 \%$, as shown in Figure 1. The source of fine aggregate is river sands which have a fineness modulus of 2.5, an apparent density of $2650 \mathrm{~kg} / \mathrm{m}^{3}$, and a bulk density of $1850 \mathrm{~kg} / \mathrm{m}^{3}$. The contents of rubber particles for the 5 different substitution rates were calculated by the equal volume substitution rate fine aggregate method. The specific mix proportions are shown in Table 1.

2.2. Experiment Equipment and Loading Scheme. As mentioned earlier, we examined the basic mechanical properties (compression, uniaxial tension, and pure shear) and the compression size effect of rubber concrete with different substitution rates. In view of that, the actual stressed environment of concrete is mainly subject to compression and restricted by loading conditions, and we only investigated the compression size effect of rubber concrete in this study. The hydraulic servo device as shown in Figure 2(a) was used to conduct uniaxial compression, uniaxial splitting, and compression size effect tests. Specifically, the uniaxial tension test was implemented using a splitting device, and the results were converted into the tensile strength in accordance with the splitting load conversion formula, as shown in Figure 2(b). The pure shear test was implemented using a material direct shear apparatus. Different from traditional concrete shear test, this equipment derives the concrete shear load by the shear dislocation method, as shown in Figure 2(c). Both the hydraulic servo and the material shear apparatus are equipped with independent load sensors and displacement sensors. The measurement precision satisfies the corresponding test requirements. Considering that the concrete materials have certain randomness and discreteness characteristics, three specimens were prepared for each working condition and the average value was used for analysis. 


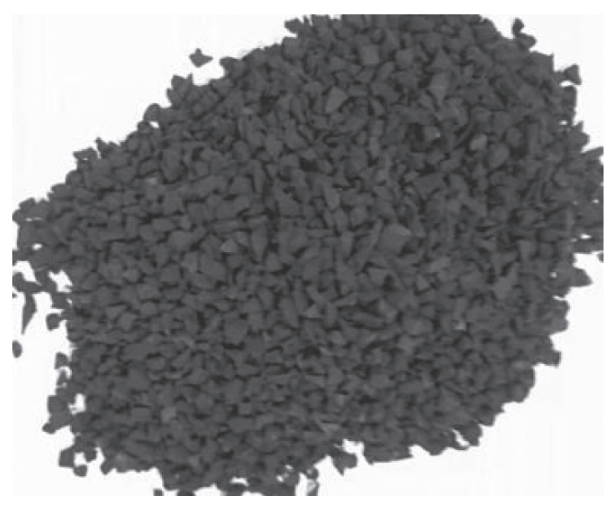

Figure 1: Rubber particles.

TABLE 1: The mix proportions of rubber concrete with different substitution rates $(\mathrm{kg})$.

\begin{tabular}{lccccc}
\hline Rubber substitution rate (\%) & Cement & Water & Fine aggregate & Rubber particles & Coarse aggregate \\
\hline 0 & 279 & 178 & 780 & 0 & 32.3 \\
10 & 279 & 178 & 702 & 64.6 & 1034 \\
20 & 279 & 178 & 624 & 96.9 & 1034 \\
30 & 279 & 178 & 546 & 129.2 & 1034 \\
40 & 279 & 178 & 468 & 1034 \\
\hline
\end{tabular}

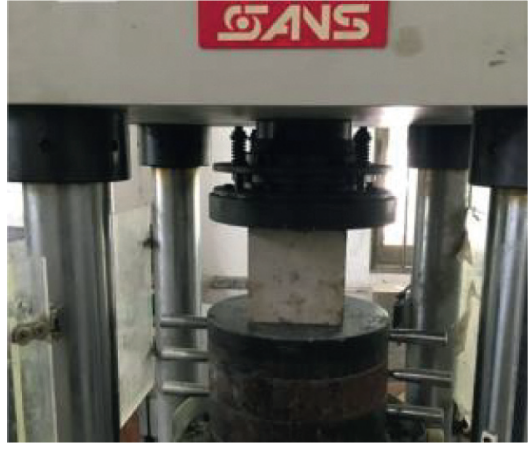

(a)

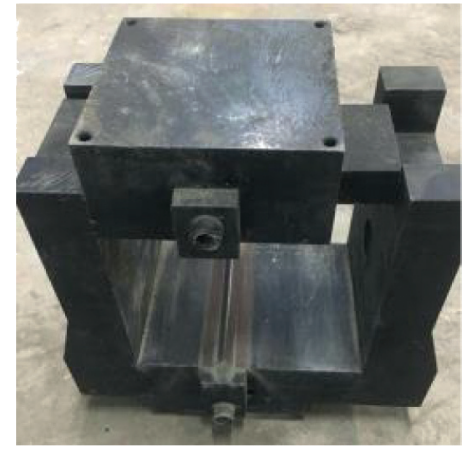

(b)

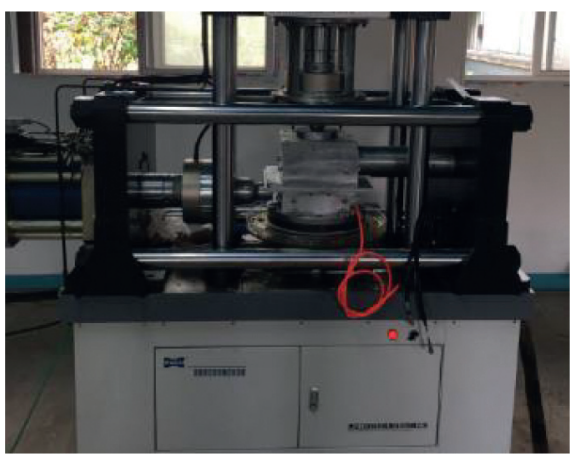

(c)

FIGURE 2: Concrete experiment equipment. (a) Schematic diagram of compression, (b) splitting device, and (c) direct shear apparatus.

In accordance with the restriction requirements of the loading device and the related literature, the specimen size for uniaxial compression and splitting tests was set to be $100 \mathrm{~mm} \times 100 \mathrm{~mm} \times 100 \mathrm{~mm}$, and the size for pure shear test was set to be $205 \mathrm{~mm} \times 205 \mathrm{~mm} \times 150 \mathrm{~mm}$ (shear section: $205 \mathrm{~mm} \times 205 \mathrm{~mm}$ ) [20]. For the study of concrete size effect, cylinder and cube are the commonly used specimen shapes. Considering the convenience of pouring, we chose the shape of cube to examine the size effect of concrete under compressive loading. Three cube sizes were designed: $70 \mathrm{~mm} \times 70 \mathrm{~mm} \times 70 \mathrm{~mm}, 100 \mathrm{~mm} \times 100 \mathrm{~mm} \times 100 \mathrm{~mm}$, and $150 \mathrm{~mm} \times 150 \mathrm{~mm} \times 150 \mathrm{~mm}$. All the tests were conducted by adopting the displacement loading control method, and the loading rate is $1 \mathrm{~mm} / \mathrm{min}$. The preloading method was used to eliminate the gap between the specimen and the device at the beginning of the test. Data was collected since the start of the test until the specimen was destroyed; i.e., loading was stopped.

\section{Analysis of Experimental Results}

\subsection{Basic Mechanical Properties}

3.1.1. Failure Modes. In accordance with the experiment plan for the uniaxial compression, uniaxial splitting, and pure shear tests of rubber concrete with different substitution rates, the failure modes of rubber concrete under different loading conditions were obtained, as shown in Figures 3-8.

Referring to the compressive failure modes of rubber concrete with different substitution rates as shown in Figures 3 and 4 , it can be seen that crack surfaces parallel to the direction of compressive loading are formed on all sides of the concrete specimens. The failure modes of rubber concrete with different substitution rates are basically similar. The difference lies in that, with the increase of rubber substitution rate, the specimen gradually exhibits a better 


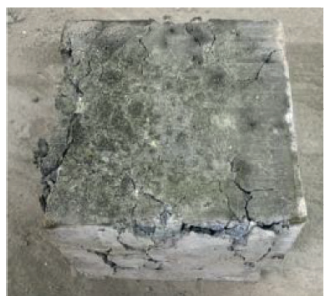

(a)

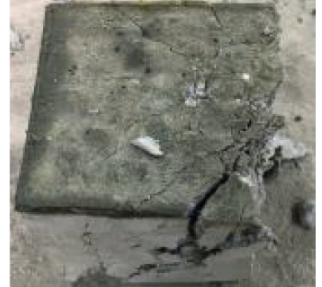

(b)

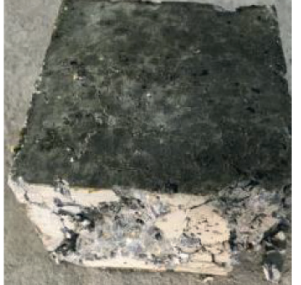

(c)

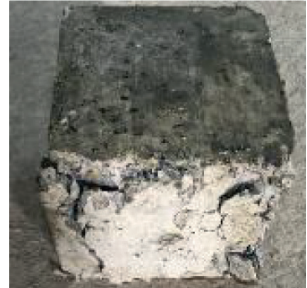

(d)

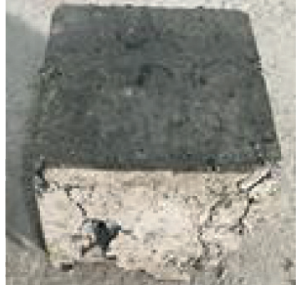

(e)

Figure 3: Compressive failure modes of rubber concrete with different substitution rates. (a) 0\%, (b) 10\%, (c) 20\%, (d) $30 \%$, and (e) $40 \%$.

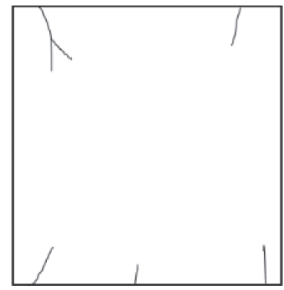

(a)

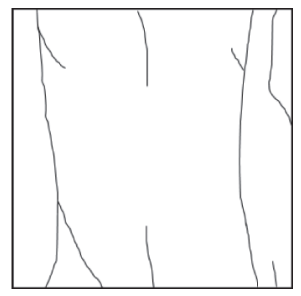

(b)

Figure 4: The failure modes of concrete under compression at different stages. (a) Initial failure mode. (b) Final failure mode.

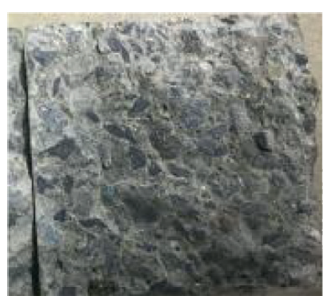

(a)

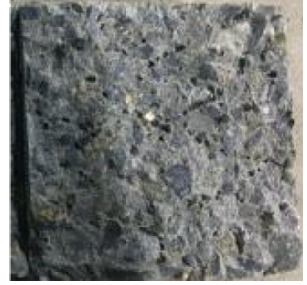

(b)

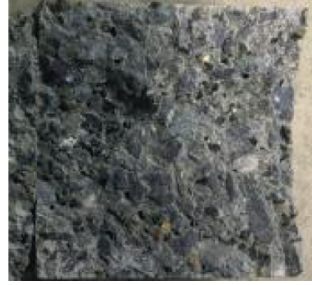

(c)

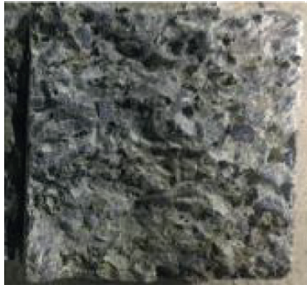

(d)

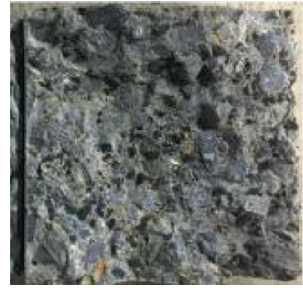

(e)

FiguRE 5: Splitting failure modes of rubber concrete with different substitution rates. (a) $0 \%$, (b) $10 \%$, (c) $20 \%$, (d) $30 \%$, and (e) $40 \%$.

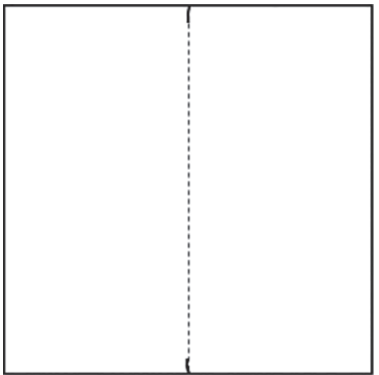

(a)

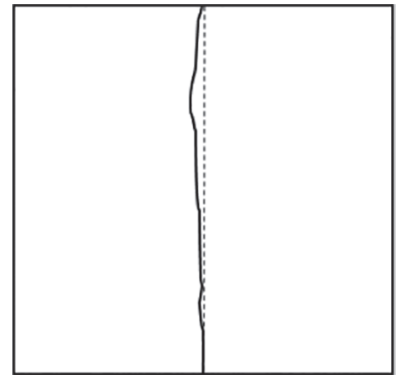

(b)

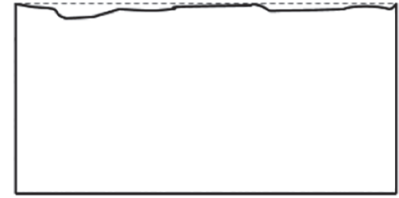

(c)

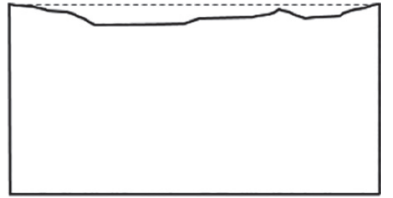

(d)

FIGURE 6: Splitting failure modes of concrete at different stages. (a) Initial failure mode, (b) final failure mode, (c) $0 \%$ failure section, and (d) $40 \%$ failure section.

integrity after being destroyed by compression with a weaker overall fragmentation; only a few rubber particles fall off from the failure section, indicating that the rubber particles have a significant modifying effect on the interface between the cement mortar and the crushed stone. Despite the difference, the failure mechanisms are the same for all specimens. Specifically, the concrete specimens are vertically compressed, which means tensile strain is formed laterally under the influence of Poisson's ratio. When the lateral tensile strain reaches the ultimate tensile strain of the concrete, the specimens will be destroyed to form the aforementioned failure modes.

Figures 5 and 6 show the splitting failure modes of rubber concrete with different substitution rates. All of the specimens exhibit the tensile failure mode after being destroyed. Under the action of the splitting device, when the tensile strain of 


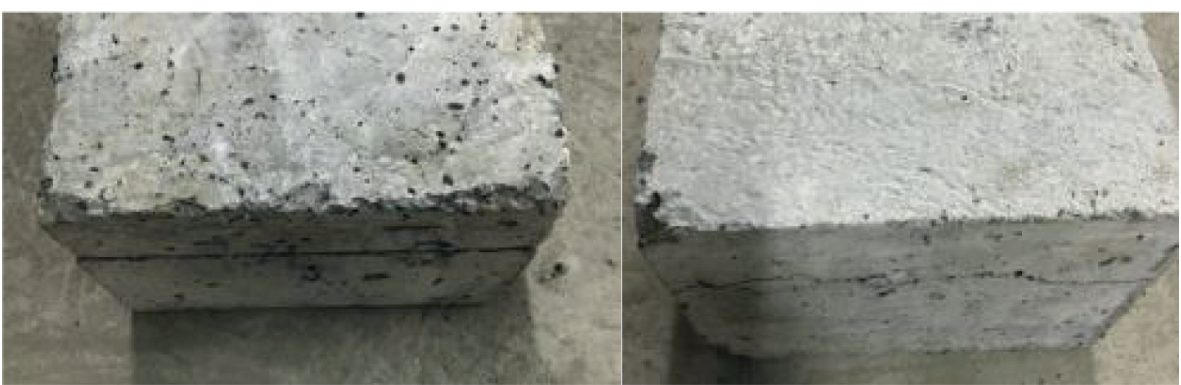

(a)

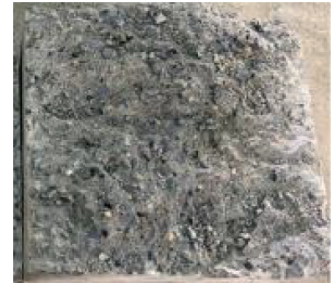

(d)

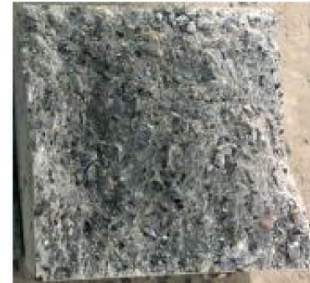

(e) (b)

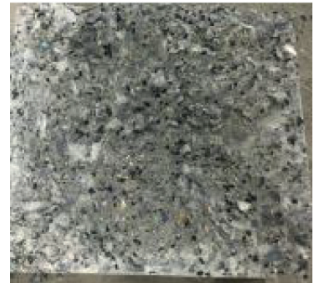

(f)

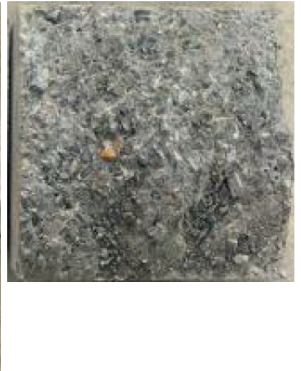

(c)

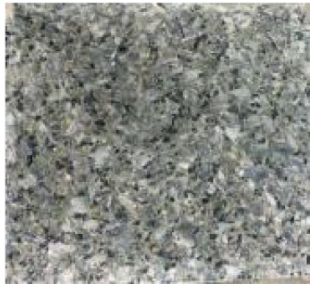

(g)

Figure 7: Pure shear failure modes of rubber concrete with different substitution rates. (a) Crack perpendicular to shear direction and (b) cracks parallel to the shear direction. (c) $0 \%$, (d) $10 \%$, (e) $20 \%$, (f) $30 \%$, and (g) $40 \%$.

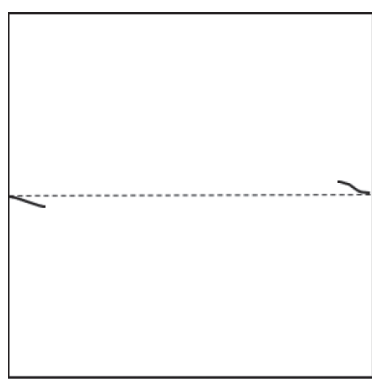

(a)

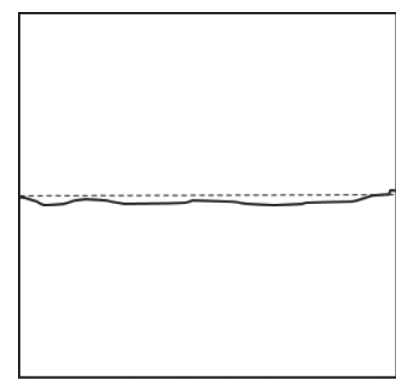

(b)

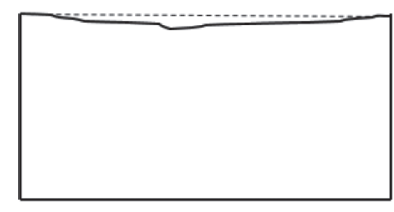

(c)

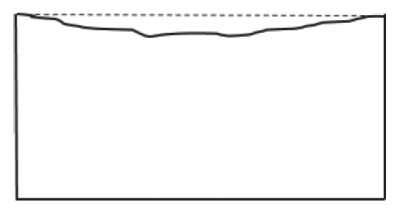

(d)

FIGURE 8: Shear failure modes of concrete in different stages. (a) Initial failure mode, (b) final failure mode, (c) $0 \%$ failure section, and (d) $40 \%$ failure section.

concrete reaches its ultimate tensile strain, the specimen will be torn and fractured. With the increase of rubber substitution rate, the splitting failure section becomes increasingly uneven, and meanwhile, the amount of rubber particles falling off from the failure section gradually increases.

Referring to the shear failure modes as shown in Figures 7 and 8, the cracks perpendicular to the shear direction are basically straight on all the rubber concrete specimens with different substitution rates, while the cracks parallel to the shear direction exhibit irregular patterns, as shown in Figures $7(\mathrm{a})$ and $7(\mathrm{~b})$. The shear failure sections of rubber concrete are shown in Figures $7(\mathrm{c})-7(\mathrm{~g})$. Obviously, the shear failure sections are similar among different specimens: they all have a relatively uneven surface, accompanied by a certain amount of concrete slag. With the increase of rubber substitution rate, the amount of rubber particles falling off from the failure section gradually increases.

When the rubber concrete is subjected to load, the rubber after the damage of the specimen falls off and adheres to a small amount of mortar. According to the weight of the falling rubber particles after the test in this paper, the amount of rubber falling off concrete with different loading modes and different rubber replacement rates is obtained. When rubber concrete is under compression, the amounts of rubber particles falling off when the rubber substitution rate is $0 \%, 10 \%, 20 \%, 30 \%$, and $40 \%$ are $0 \mathrm{~g}, 0.9 \mathrm{~g}, 1.7 \mathrm{~g}, 2.3 \mathrm{~g}$, and $3.5 \mathrm{~g}$, respectively. When concrete is subjected to splitting, the amount of rubber particles falling off is $0 \mathrm{~g}, 1.2 \mathrm{~g}, 2.3 \mathrm{~g}$, $2.9 \mathrm{~g}$, and $3.9 \mathrm{~g}$, respectively. When the rubber concrete is subjected to shearing, the amount of rubber particles falling off is $0 \mathrm{~g}, 2.9 \mathrm{~g}, 4.3 \mathrm{~g}, 5.4 \mathrm{~g}$, and $7.6 \mathrm{~g}$. In contrast, rubber concrete is subjected to shearing, and the amount of rubber particles falling off after concrete is relatively large.

3.1.2. Stress-Strain Curve. Based on the load and deformation data of rubber concrete with different substitution rates collected from the tests under uniaxial compression, uniaxial splitting, and pure shear loading conditions, the stress-stain curves of rubber concrete were obtained as shown in Figure 9. 


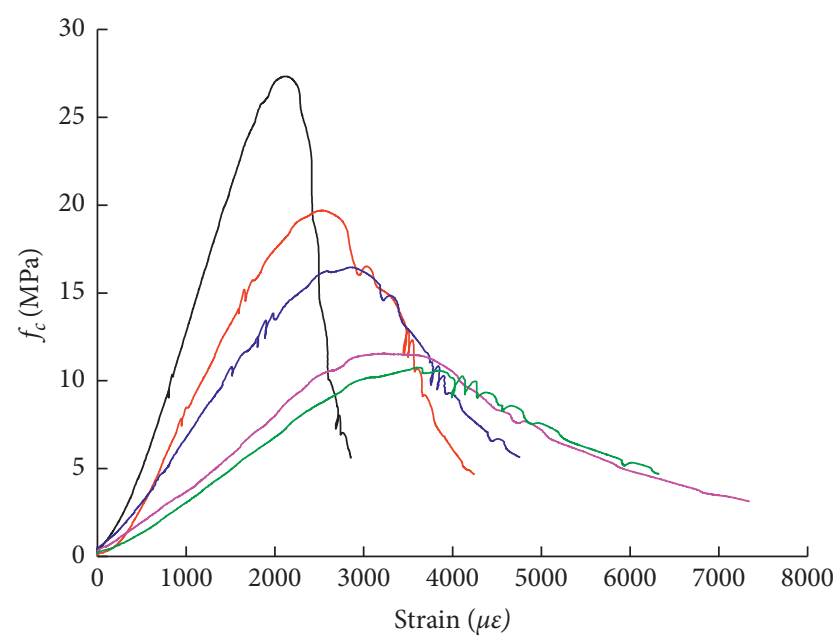

$\begin{array}{ll}-0 \% \text { rubber particles } & -30 \% \text { rubber particles } \\ -10 \% \text { rubber particles } & -40 \% \text { rubber particles } \\ \text { 20\% rubber particles } & \end{array}$

(a)

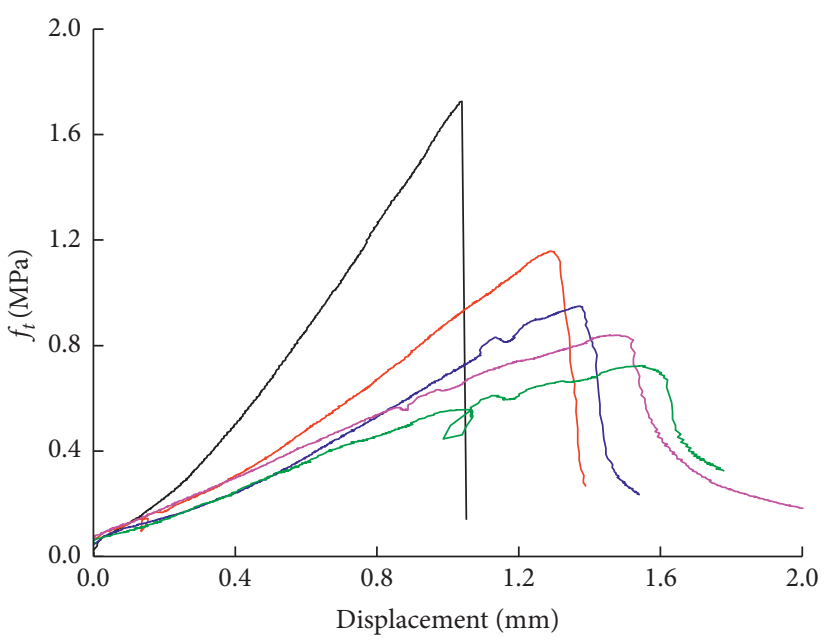

$\begin{array}{ll}-0 \% \text { rubber particles } & -30 \% \text { rubber particles } \\ -10 \% \text { rubber particles } & \quad \text { 40\% rubber particles } \\ -20 \% \text { rubber particles } & \end{array}$

(b)

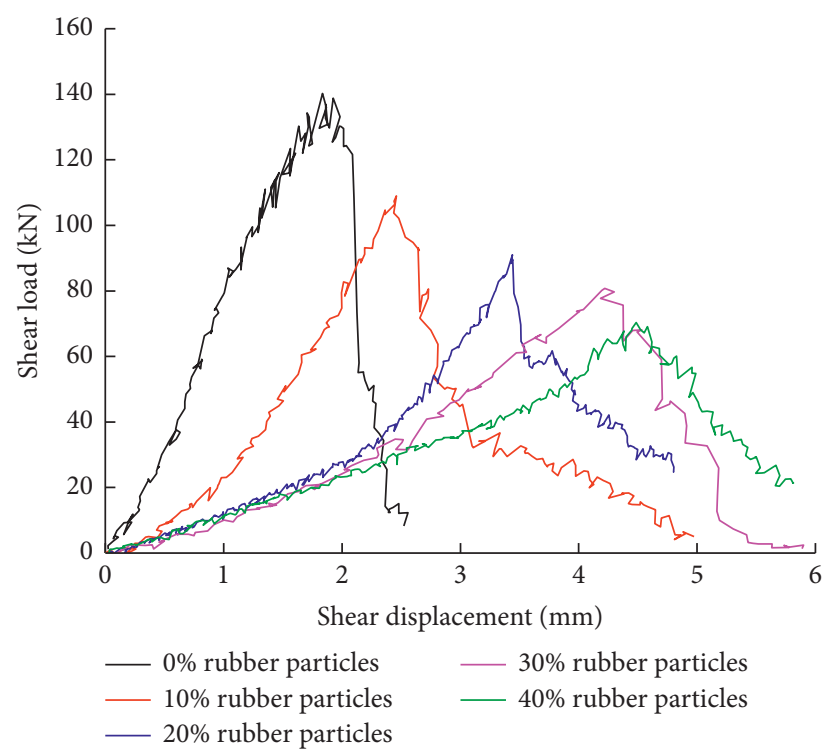

(c)

FiguRE 9: Stress-strain curves of rubber concrete specimens with different substitution rates under uniaxial loading. (a) Uniaxial compression, (b) uniaxial splitting, and (c) pure shear.

Figure 9(a) shows the stress-strain curves of rubber concrete specimens with different substitution rates under uniaxial compression. As can be seen, the compressive stress-strain curves of rubber concrete with different substitution rates exhibit a similar developing pattern, which can be divided into the elastic stage, the elastoplastic stage, and the declining stage. Specifically, the stress-strain curves start with an elastic stage, and as the load continues to increase, the concrete will evolve into the elastoplastic stage. When the load reaches the failure load of the concrete, the curve begins to decline and enter the declining stage. The stress-strain curves of all rubber concrete specimens show good continuity and smoothness. However, with the increase of rubber substitution rate, the compressive strength of rubber concrete obviously decreases, while the peak strain shows an increasing trend; at the same time, the plastic deformation capacity gradually increases.

Figure 9(b) shows the stress-deformation curves of rubber concrete specimens with different substitution rates under uniaxial splitting. The stress-strain curves of various specimens can be divided into two stages: a straight-line rising stage and a declining stage. In accordance with the preliminary analysis of the splitting stress-deformation curve, the splitting stress of concrete gradually decreases with the increase of rubber substitution rate, while the peak deformation gradually increases at the same time.

Figure 9(c) shows the load-displacement curves of rubber concrete specimens with different substitution rates 
under pure shear. As can be seen, the curves of concrete specimens with different substitution rates basically exhibit the same developing trend. With the increase of rubber substitution rate, the shear failure load of rubber concrete gradually decreases, while the peak displacement gradually increases. A possible explanation is that the increase of rubber substitution rate weakens the shear failure section of the rubber concrete; because the adhesive capacity between rubber particles and the cementing material and between rubber particles and the crushed stone is relatively low, the concrete shear load eventually shows a decreasing trend with the increase of rubber substitution rate. Meanwhile, the deformation capacity of rubber particles is much greater than that of the fine aggregate river sands; therefore, the peak displacement of rubber concrete gradually increases. The effect of rubber substitution rate on the strength and deformation of rubber concrete specimens under the compression and splitting loading modes can be explained by the same mechanism as that of the shear loading mode.

3.1.3. Characteristic Strength. In accordance with the uniaxial load-deformation curves of rubber concrete with different substitution rates as shown in Figure 9, we derived the ultimate strength of the load-deformation curve to analyze the effect of rubber substitution rate on the ultimate strength eigenvalue of rubber concrete as shown in Figure 10.

Figure 10(a) illustrates how the ultimate strength eigenvalue of rubber concrete varies along with the rubber substitution rate. When the substitution rate is equal to $0 \%$ (i.e., ordinary concrete), the uniaxial compressive strength is equal to $25.94 \mathrm{MPa}$. Then, the uniaxial compressive strength gradually decreases as the rubber substitution rate increases. Specifically, the compressive strength of concrete corresponding to the rubber substitution rate of $10 \%, 20 \%$, and $30 \%$ is equal to $18.71 \mathrm{MPa}$, 15.63 $\mathrm{MPa}$, and $10.97 \mathrm{MPa}$, respectively. When the rubber substitution rate is equal to $40 \%$, the uniaxial compressive strength is equal to $10.21 \mathrm{MPa}$, suggesting a decrease of $60.67 \%$. In accordance with Figure 10(b), the splitting tensile stress of concrete shows a decreasing trend as the rubber substitution rate increases. When the substitution rate is equal to $0 \%$, the splitting tensile stress is equal to $1.45 \mathrm{MPa}$. When the rubber substitution rate increases to $10 \%, 20 \%$, and $30 \%$, the corresponding splitting tensile strength is equal to $0.99 \mathrm{MPa}, 0.81 \mathrm{MPa}$, and $0.71 \mathrm{MPa}$, respectively. When the rubber substitution rate further increases to $40 \%$, the splitting tensile strength decreases to $0.61 \mathrm{MPa}$, which is $58.38 \%$ lower than that of ordinary concrete. In accordance with Figure 10(c), the shear strength of concrete gradually decreases as the rubber substitution rate increases. When the rubber substitution rate is equal to $0 \%$, the shear strength is equal to $3.34 \mathrm{MPa}$. When the substitution rate increases to $10 \%, 20 \%$, and 30 , the corresponding shear strength is equal to $2.59 \mathrm{MPa}$, $2.17 \mathrm{MPa}$, and $1.92 \mathrm{MPa}$, respectively. When the substitution rate further increases to $40 \%$, the shear strength decreases to $1.67 \mathrm{MPa}$, which is $49.85 \%$ lower than that of ordinary concrete.
In accordance with the characteristics of concrete materials, there exists chemical adhesion between mortar and mortar, and between mortar and coarse aggregate, regardless of the actions of compression, splitting, or shear. This chemical adhesive effect is mainly related to the composition characteristics of mortar. With the increase of rubber substitution rate, the boding between rubber particles and mortar will be weakened, which leads to a lower chemical adhesion in the rubber concrete; eventually, the mechanical properties of rubber concrete will gradually decrease. At the same time, the bearing capacity of rubber particles is much lower than that of fine aggregate river sands, and therefore, the ultimate strength of concrete is gradually weakened as the rubber replacement rate increases.

In literature [1], the relationship equation between the compressive strength and tensile strength of ordinary concrete is given as shown in (1), and the corresponding experimental and theoretical values are shown in Figure 11. The relationship equation between the compressive strength and shear strength is given in (2), and the corresponding experimental and theoretical values are shown in Figure 12:

$$
\begin{aligned}
f_{t} & =0.19 f_{\mathrm{cu}}^{0.75}, \\
\tau & =0.38 f_{\mathrm{cu}}^{0.57},
\end{aligned}
$$

where $f_{t}$ is the splitting strength of concrete; $f_{\text {cu }}$ is the compressive strength of concrete; $\tau$ is the shear strength of concrete.

In accordance with Figures 11-12, we compared the theoretical value of splitting strength that was calculated from the compressive strength with the experimental value of splitting strength. It is found that the difference between the theoretical value and experimental value is insignificant when the rubber substitution rate is equal to $0 \%$ (i.e., the ordinary concrete). However, there is a significant difference between the theoretical value and experimental value for the other four rubber substitution rates. A possible reason is that the theoretical values are derived based on the experimental data of ordinary concrete, and therefore, the theoretical values calculated for rubber concrete would have a relatively big difference from the experimental values. In our study, the relationship between the compressive strength and splitting strength of ordinary concrete has an obvious difference from the empirical calculation formula. This can be mainly explained from two aspects. First, the basic characteristics of concrete materials: in view of the contact between concrete mortar and coarse aggregate as well as the quality of pouring, concrete is featured with the randomness and discreteness characteristics, which impose a certain impact on the compressive strength and splitting strength of concrete. The existing studies on concrete characteristics suggest that the discreteness of concrete strength can be up to $15 \%$ due to the randomness and discreteness effects [1]. Secondly, our tensile experiment was carried out by splitting, but for the empirical calculation formula, the tensile strength is obtained by performing mathematical regression summary on the experimental data derived from various tensile loading modes such as direct stretching, splitting, and bending. In 


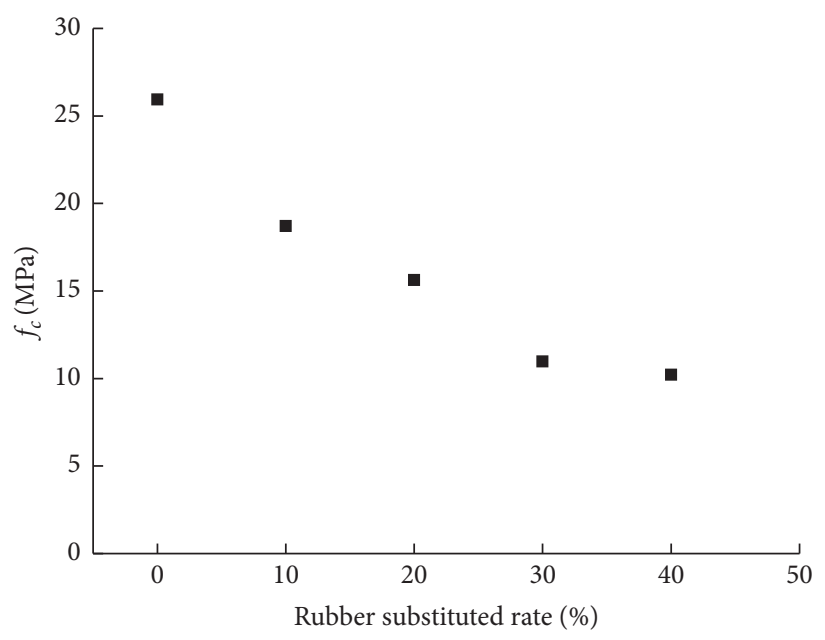

- Rubberized concrete

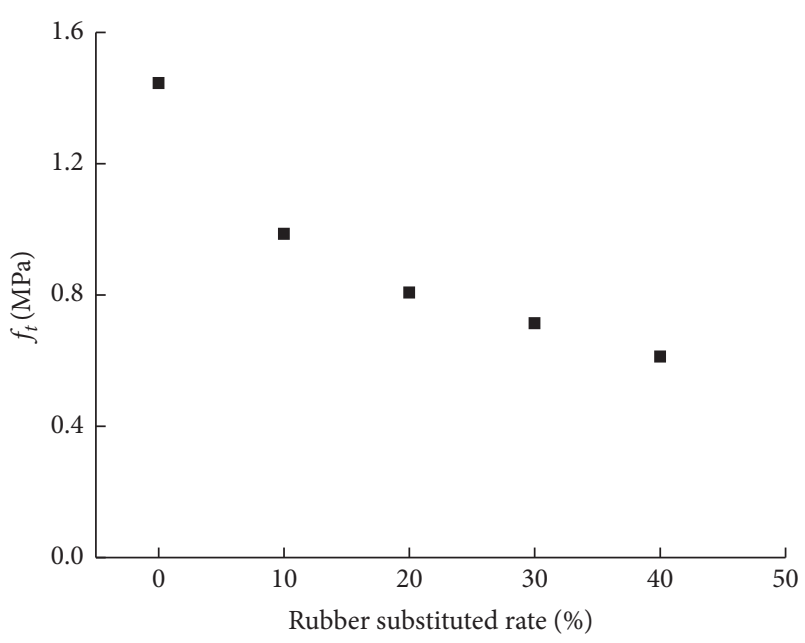

- Rubberized concrete

(a)

(b)

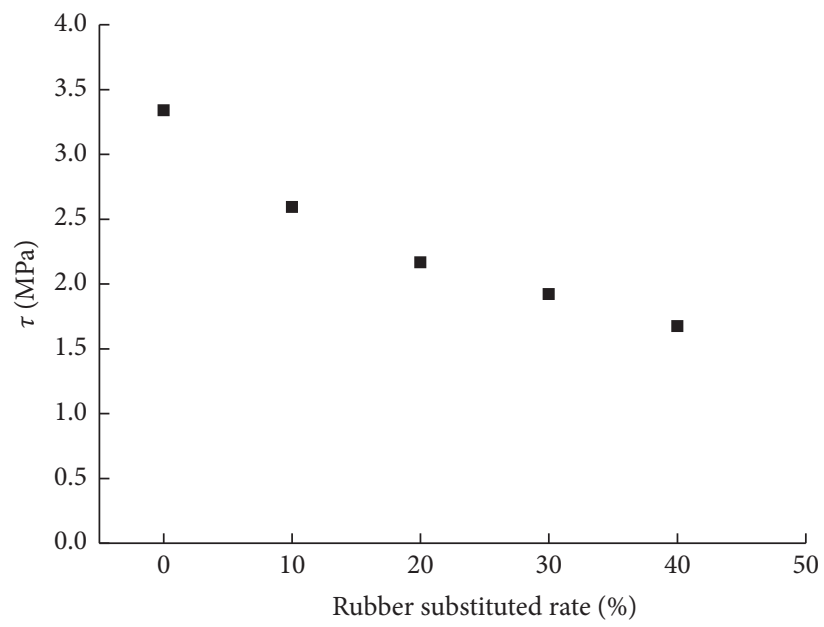

Rubberized concrete

(c)

Figure 10: Effect of rubber substitution rate on the ultimate strength eigenvalue of rubber concrete. (a) Uniaxial compression, (b) uniaxial splitting, and (c) pure shear.

view of the coupling effect of these two aspects, the relationship between the compressive strength and splitting strength of ordinary concrete in our study shows an obvious difference from the empirical calculation formula.

Based on the analysis of the relationship between the compressive strength and shear strength of concrete, it is found that the theoretical value of ordinary concrete differs from the experimental value by $26.95 \%$, while the errors of all rubber concrete specimens are lower than that of ordinary concrete. Specifically, the concrete specimen with $40 \%$ rubber particles has the smallest error, which is $14.37 \%$. On the other hand, different from the compression and tension tests, the shear test lacks a standard procedure. Generally, the shear data is obtained by indirect measurement methods, such as the direct shear test of rectangular short beam, the single-shear test of Z-shaped column, and the four-point stress test of notched beam; however, the shear loads obtained by different test methods have a great difference, which can be up to $2 \sim 3$ times [1]. In this study, we directly measured the shear load of concrete by applying the direct shear method, which is a relatively accurate approach. Nevertheless, there is still a certain level of difference between the experimental value and the theoretical value.

In accordance with the composition characteristics of rubber concrete, we simplified the structure of rubber particles into a circular particle model as shown in Figure 13, in order to facilitate the analysis on the mechanism of rubber particles in rubber concrete under the three different loading modes.

As shown in Figure 13, based on the analysis of the basic mechanical properties of rubber concrete with different substitution rates, it is found that, with the increase of rubber substitution rate, the concrete strength gradually decreases while the degree of deformation gradually increases. To find 


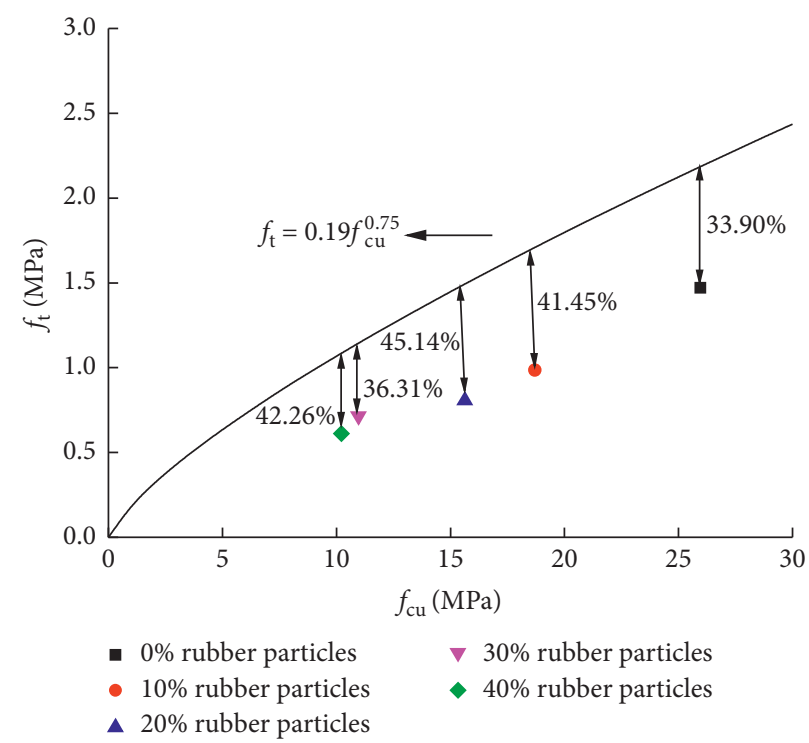

FIGURE 11: Relationship equation between the compressive strength and tensile strength of concrete.

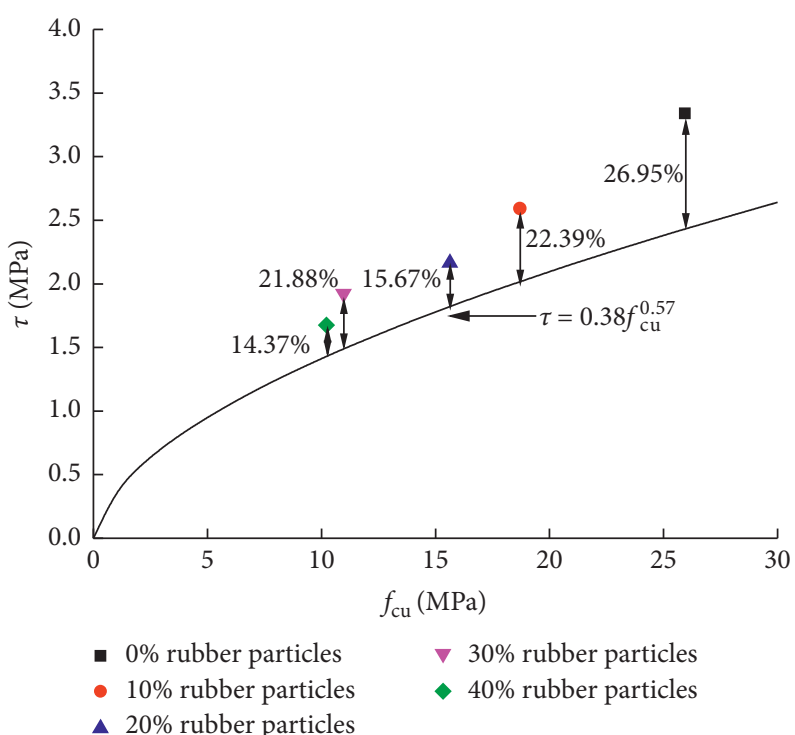

FIGURE 12: Relationship equation between the compressive strength and shear strength of concrete.

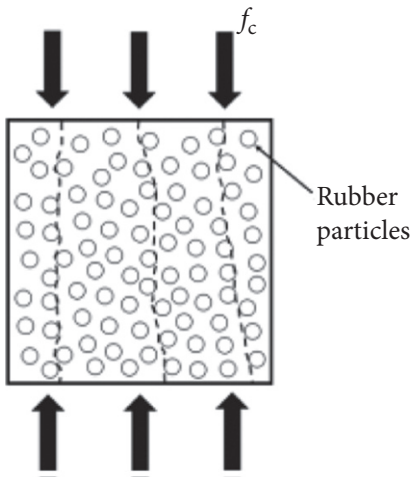

(a)

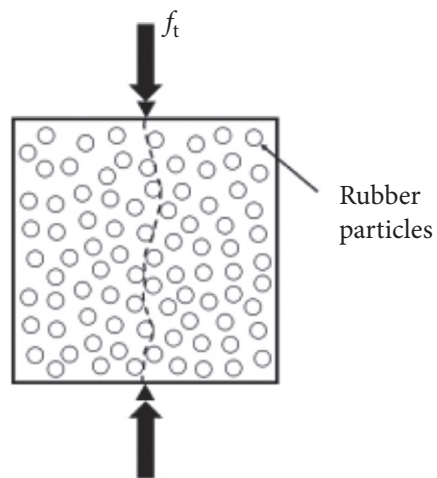

(b)

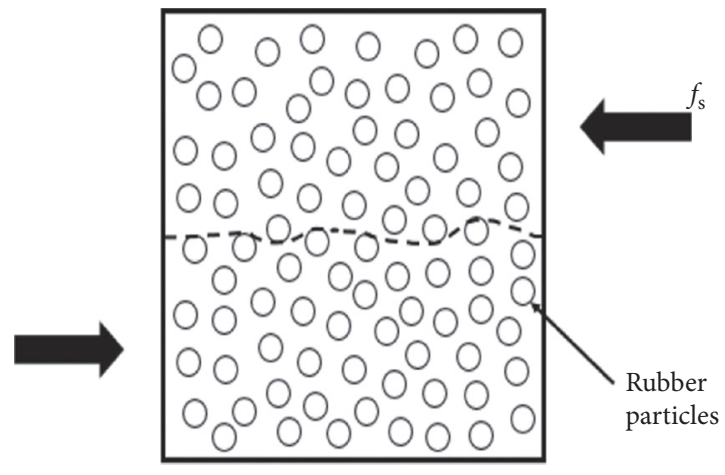

(c)

FiguRE 13: Failure mechanisms of rubber concrete under different loading modes. (a) uniaxial compression, (b) uniaxial tension, and (c) pure shear. 
out whether there exists a best performance point for the strength and deformation of rubber concrete, two aspects must be considered. First, the rubber concrete should be designed with a relatively high substitution rate in order to exert its impact resistance, crack resistance, and toughness as much as possible. Second, the rubber concrete should be designed with a relatively high strength and low degree of deformation. Referring to Eldin's [5] research on the mechanical properties of rubber concrete with $100 \%$ of rubber substitution for fine aggregate, the compressive strength and splitting strength of concrete were reduced by $65 \%$ and $50 \%$, respectively. Miller and Tehrani [21] reported that the compressive strength and splitting strength of rubber concrete were at a relatively stable level when the substitution rate was equal to $40 \%$; when the substitution rate exceeded $40 \%$, the change of concrete strength was relatively small, but the change of deformation was relatively significant. In our study, it is found that the compressive strength and splitting tensile strength are reduced by $60.67 \%$ and $58.38 \%$, respectively, when the rubber substitution rate is equal to $40 \%$. Combining with the literature findings, the rubber concrete can guarantee a relatively stable strength and a better deformation performance while being able to exert the advantage of rubber concrete as much as possible at the substitution rate of $40 \%$.

\subsection{Size Mechanical Properties}

3.2.1. Failure Mode. With respect to the compression size effect of rubber concrete, we analyzed the size effect on the mechanical properties of rubber concrete with different substitution rates based on the failure mode from a macroscopic perspective. Subject to space limitation, we only performed failure mode analysis for the rubber substitution rates of $0 \%, 20 \%$, and $40 \%$ in this study, as shown in Figure 14.

In accordance with Figure 14, it is found that, at the same rubber substitution rate, the integrity of concrete is gradually improved as the cubic side length increases. All the specimens exhibit the same failure mode and crack development mode, indicating that the size effect has no impact on the failure mechanism and failure development of the rubber concrete with various substitution rates.

3.2.2. Characteristic Strength. In accordance with our prespecified loading scheme, we obtained the compressive strength eigenvalues of rubber concrete with different substitution rates $(0 \%, 10 \%, 20 \%, 30 \%$, and $40 \%)$ and different cubic side lengths $(70 \mathrm{~mm}, 100 \mathrm{~mm}$, and $150 \mathrm{~mm})$. Then, the influence of size effect and rubber substitution rate on the mechanical properties of rubber concrete was analyzed based on the compressive strength eigenvalues, as shown in Table 2.

It can be seen from Table 2 that the strength of rubber concrete gradually decreases as the rubber substitution rate increases. For $70 \mathrm{~mm}$ specimens, the compressive strength decreases from $29.89 \mathrm{MPa}$ ( $0 \%$ of rubber particles) to $10.96 \mathrm{MPa}$ (40\% of rubber particles) with the increase of rubber substitution rate, i.e., a percentage reduction of $63.33 \%$. For $100 \mathrm{~mm}$ specimens, the compressive strength decreases from $25.94 \mathrm{MPa}(0 \%$ of rubber particles) to $10.21 \mathrm{MPa}$ (40\% of rubber particles), i.e., a maximum percentage reduction of $60.64 \%$. For $150 \mathrm{~mm}$ specimens, the compressive strength decreases from $23.03 \mathrm{MPa}(0 \%$ of rubber particles) to $9.53 \mathrm{MPa}$ ( $40 \%$ of rubber particles), i.e., a maximum percentage reduction of $58.62 \%$. With the increase of rubber substitution rate, the percentage reduction of compressive strength is similar among specimens of different sizes (a difference within 5\%), suggesting that the effect of rubber substitution rate on the compressive strength of rubber concrete is basically independent of the size effect. A possible reason is that, for the concrete specimens with different sizes but the same rubber substitution rate, although the net weights of rubber particles contained in the concrete specimens are different, the percentage content of rubber particles remains the same; therefore, the concrete specimens are basically affected by rubber particles to a similar degree, and eventually, the changes of compressive strength in concrete specimens of different sizes affected by the same rubber substitution rate are similar.

Meanwhile, in accordance with the analysis of our experimental data, it is found that the compressive strength of rubber concrete is significantly affected by the rubber substitution rate when the substitution rate is $\leq 20 \%$, while the compressive strength of rubber concrete is relatively weakly affected by the rubber substitution rate when the substitution rate is $>20 \%$. This is consistent with literature [21] under the same mechanism. Specifically, when rubber particles are added to the concrete, the bonding effect between the rubber particles and the cementing material will be significantly weakened; furthermore, the cylinder compressive strength of rubber particles is lower than that of fine aggregate, which makes the compressive strength of rubber concrete lower than that of ordinary concrete. Since rubber particles are mainly used to replace fine aggregate in the concrete, the content and characteristics of coarse aggregate remain unchanged. Further, the interactions between coarse aggregate and coarse aggregate and between coarse aggregate and mortar play an important role in bearing the compression load. Therefore, when the rubber substitution rate reaches a certain level, the influence on the bonding interface and aggregate cylinder compressive strength gradually enters a relatively stable stage, and consequently, the decreasing amplitude of the compressive strength is gradually reduced with further increase of the rubber substitution rate. In addition, based on preliminary analysis of Table 2 , for the same rubber substitution rate, the compressive strength of concrete gradually decreases as the specimen size increases, and the concrete specimens with different substitution rates all exhibit a significant size effect.

3.2.3. Size Effect. The quantitative study of concrete size effect is generally conducted from two perspectives, the size effect ratio and the size effect law [19]. In this paper, the size effect on the compressive strength eigenvalues of rubber 


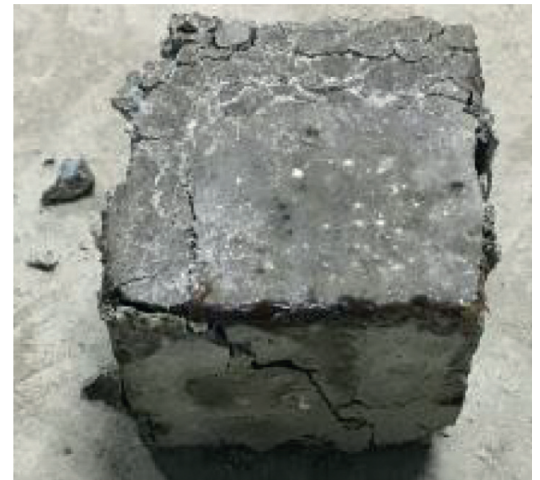

1) $70 \mathrm{~mm} \times 70 \mathrm{~mm} \times 70 \mathrm{~mm}$

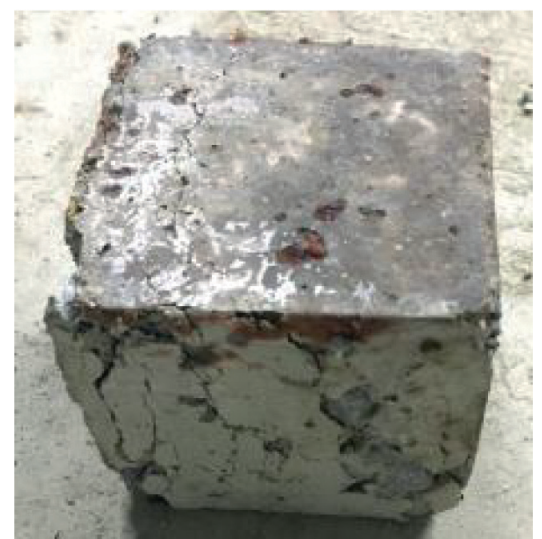

1) $70 \mathrm{~mm} \times 70 \mathrm{~mm} \times 70 \mathrm{~mm}$

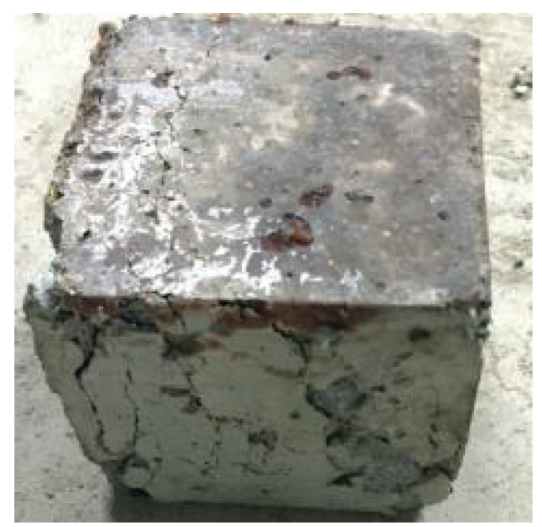

1) $70 \mathrm{~mm} \times 70 \mathrm{~mm} \times 70 \mathrm{~mm}$

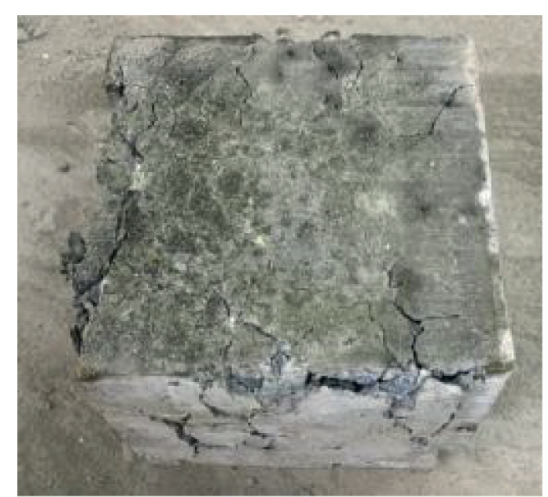

2) $100 \mathrm{~mm} \times 100 \mathrm{~mm} \times 100 \mathrm{~mm}$

(a)

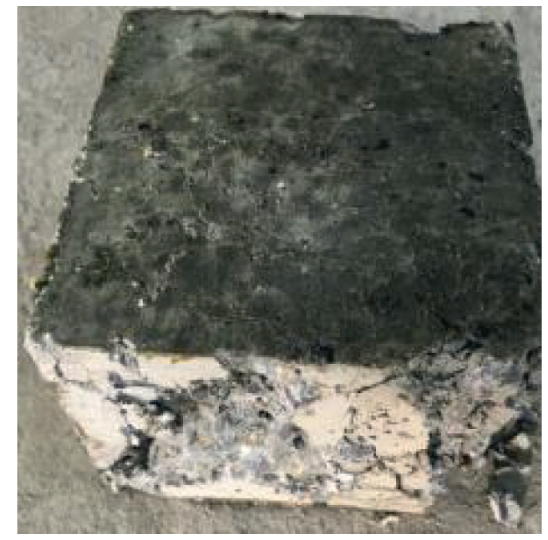

2) $100 \mathrm{~mm} \times 100 \mathrm{~mm} \times 100 \mathrm{~mm}$

(b)

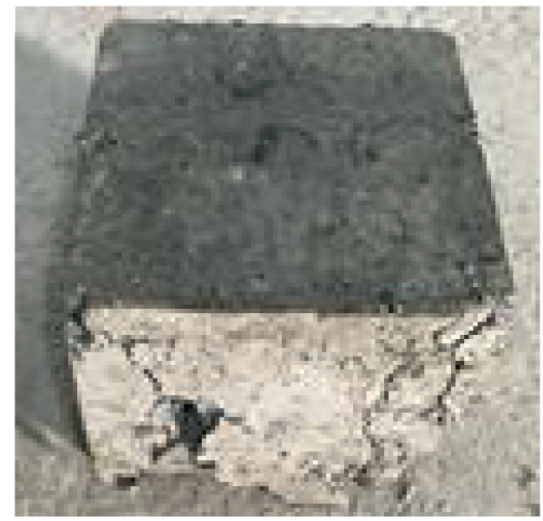

2) $100 \mathrm{~mm} \times 100 \mathrm{~mm} \times 100 \mathrm{~mm}$

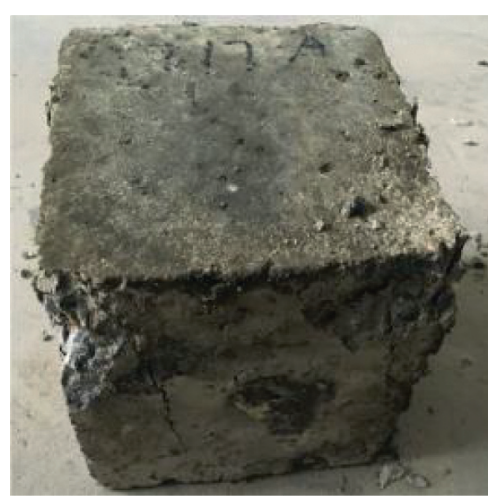

3) $150 \mathrm{~mm} \times 150 \mathrm{~mm} \times 150 \mathrm{~mm}$

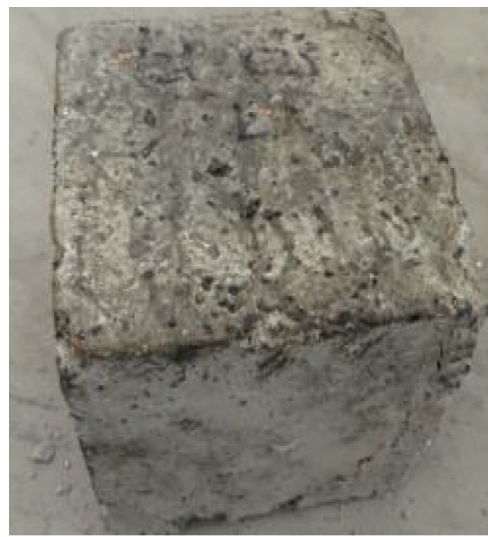

3) $150 \mathrm{~mm} \times 150 \mathrm{~mm} \times 150 \mathrm{~mm}$

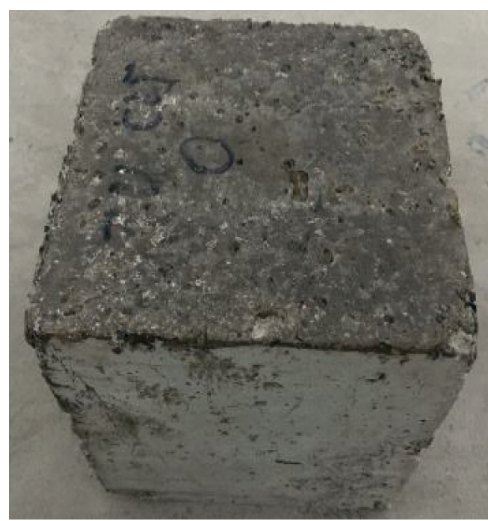

3) $150 \mathrm{~mm} \times 150 \mathrm{~mm} \times 150 \mathrm{~mm}$

(c)

FIGURE 14: Failure modes of rubber concrete with different substitution rates under compression size effect ((1)70 $\mathrm{mm} \times 70 \mathrm{~mm} \times 70 \mathrm{~mm}$, $(2)$ $100 \mathrm{~mm} \times 100 \mathrm{~mm} \times 100 \mathrm{~mm}$, and (3) $150 \mathrm{~mm} \times 150 \mathrm{~mm} \times 150 \mathrm{~mm}$ ). (a) Rubber particles $0 \%$, (b) rubber particles $20 \%$, and (c) rubber particles $40 \%$.

TABLE 2: Strength eigenvalues of rubber concrete (MPa).

\begin{tabular}{lcccrr}
\hline Size $(\mathrm{mm})$ & \multicolumn{4}{c}{ Rubber (\%) } \\
& 0 & 10 & 20 & 30 & 11.92 \\
\hline 70 & 29.89 & 20.92 & 17.02 & 10.96 \\
100 & 25.94 & 18.71 & 15.63 & 10.97 & 10.21 \\
150 & 23.03 & 16.86 & 14.35 & 9.53 \\
\hline
\end{tabular}


concrete with different substitution rates was also analyzed from these two perspectives.

(1) Size Effect Ratio. Size effect ratio refers to the quantitative expression of the relationship between the compressive strength of a concrete specimen with a reference size and the compressive strength of a concrete specimen with a nonreference size, which is usually expressed by the parameter $\gamma$. In accordance with the sizes of rubber concrete specimens used in our study, the specimen with the smallest side length $(70 \mathrm{~mm} \times 70 \mathrm{~mm} \times 70 \mathrm{~mm})$ was set as the reference specimen by referring to literature [19], in order to facilitate our analysis. Then, the specimens with the side length of $100 \mathrm{~mm}$ and $150 \mathrm{~mm}$ were considered as nonreference specimens. The size effect ratio can be calculated by

$$
\begin{aligned}
& \gamma_{100}=\frac{f_{\mathrm{cu}, 100}-f_{\mathrm{cu}, 70}}{f_{\mathrm{cu}, 70}} \times 100 \%, \\
& \gamma_{150}=\frac{f_{\mathrm{cu}, 150}-f_{\mathrm{cu}, 70}}{f_{\mathrm{cu}, 70}} \times 100 \% .
\end{aligned}
$$

In accordance with the compressive strength eigenvalues of the rubber concrete with different substitution rates and cube sizes, we calculated the size effect ratio for each specimen by applying equations (3) and (4), as shown in Table 3.

It can be seen from Table 3 that, for the $100 \mathrm{~mm}$ specimens, the size effect ratio corresponding to the rubber substitution rate of $0 \%, 10 \%, 20 \%, 30 \%$, and $40 \%$ is equal to $13.22 \%, 10.56 \%, 8.17 \%, 7.97 \%$, and $6.84 \%$, respectively; for the $150 \mathrm{~mm}$ specimens, the size effect ratio corresponding to the rubber substitution rate of $0 \%, 10 \%, 20 \%, 30 \%$, and $40 \%$ is equal to $22.95 \%, 19.41 \%, 15.69 \%, 14.38 \%$, and 13.05 , respectively. Obviously, the size effect on the compressive strength of concrete becomes less significant as the rubber substitution rate increases.

The underlying mechanism for the experimental results above can be explained as follows: the amount of internal cracks and the crack size of the concrete increase accordingly as the specimen size increases, which consequently makes the compressive strength decrease gradually. With respect to the influence of rubber substitution rate on the size effect, rubber concrete has a weaker brittleness compared to ordinary concrete; with the increase of substitution rate, the brittleness of concrete gradually decreases. There is a close association between the size effect and the brittleness of concrete, based on which the experimental results mentioned above were obtained. At the same time, in accordance with the data analysis of extensive literature [17-19], the concrete specimens with a greater compressive strength are more significantly affected by the size effect, which further confirms our research conclusions; i.e., with the increase of rubber substitution rate, the compressive strength size effect of the rubber concrete becomes less significant.

(2) Size Effect Law. In the study of size effect of concrete materials, the size effect energy release criterion explains that the strain energy released by concrete (as a quasibrittle
TABLE 3: Size effect ratio of rubber concrete.

\begin{tabular}{lccccc}
\hline \multirow{2}{*}{ Size effect ratio (\%) } & \multicolumn{5}{c}{ Rubber (\%) } \\
& 0 & 10 & 20 & 30 & 40 \\
\hline$\gamma_{100}$ & 13.22 & 10.56 & 8.17 & 7.97 & 6.84 \\
$\gamma_{150}$ & 22.95 & 19.41 & 15.69 & 14.35 & 13.05 \\
\hline
\end{tabular}

material) due to crack development under the loading condition leads to the existence of size effect. In accordance with the deformation coordination and energy balance, Bazant [22] proposed the relationship between the nominal compressive strength of concrete $\sigma_{N}$ and the specimen size $D$, i.e., the size effect law formula, as shown in

$$
\sigma_{N}=\sigma_{\infty}\left(1+\frac{D_{b}}{D}\right)
$$

where $\sigma_{\infty}$ refers to the compressive strength eigenvalue of an infinitely large specimen (MPa); $D_{b}$ is the structural characteristic size $(\mathrm{mm})$.

In accordance with our experimental data related to the compressive strength of rubber concrete with different substitution rates, the expression for the size effect law of rubber concrete as shown in Figure 15(a) and the mathematical regression parameter values of the size effect law for rubber concrete specimens with different substitution rates as shown in Table 4 were obtained by performing mathematical regression analysis per (5).

In accordance with Figure 15(a) and Table 4, the equation of size effect law has a high level of applicability to the quantitative study and prediction of the compression size effect of rubber concrete with different substitution rates. To further examine the size effect on the compressive strength of rubber concrete, we performed dimensionless treatment to the data by referencing to literature [19] and obtained the unified equation of size effect law, as shown in (6). This equation can be used to study the influence of the rubber substitution rate on the compressive strength size effect of rubber concrete.

$$
\frac{\sigma_{N}}{\sigma_{70}}=\frac{\sigma_{\infty}}{\sigma_{70}}\left(1+\frac{b}{D}\right)
$$

Based on the experimental data of the compressive strength eigenvalues of rubber concrete specimens with different cubic sizes, we obtained the quantitative expression for the size effect of rubber concrete under the compression loading mode, as shown in Figure 15(b) and equation (7), by performing mathematical regression analysis using equation (6):

$$
\frac{\sigma_{N}}{\sigma_{70}}=0.68076 \times\left(1+\frac{32.90323}{D}\right), \quad R^{2}=0.88 .
$$

In accordance with Figure 15(b) and equation (7), the unified equation of size effect law is consistent with the qualitative research conclusions derived from the experimental data of the compressive strength size effect. From Figure 15(b), it can be found that the concrete specimens with $0 \%$ rubber participles are the most significantly affected 


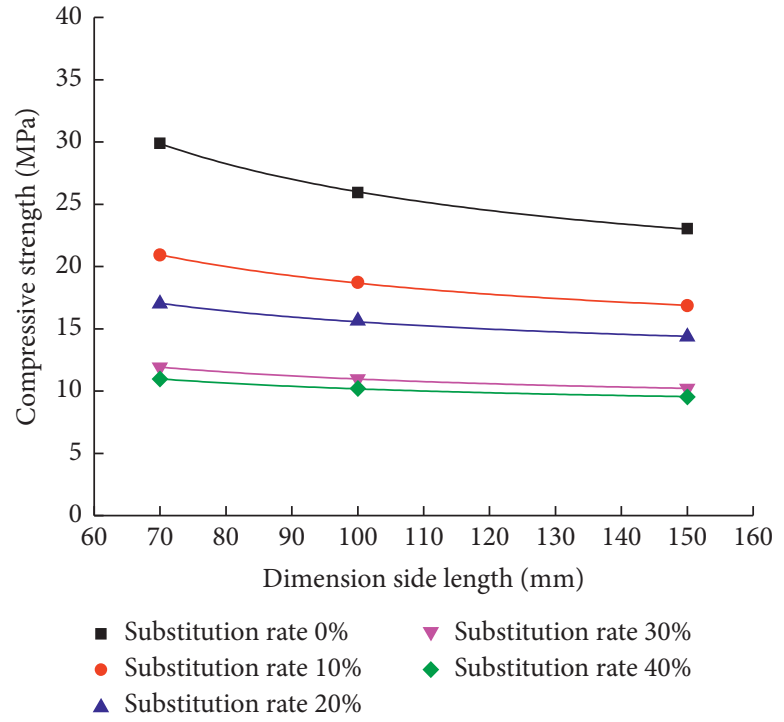

(a)

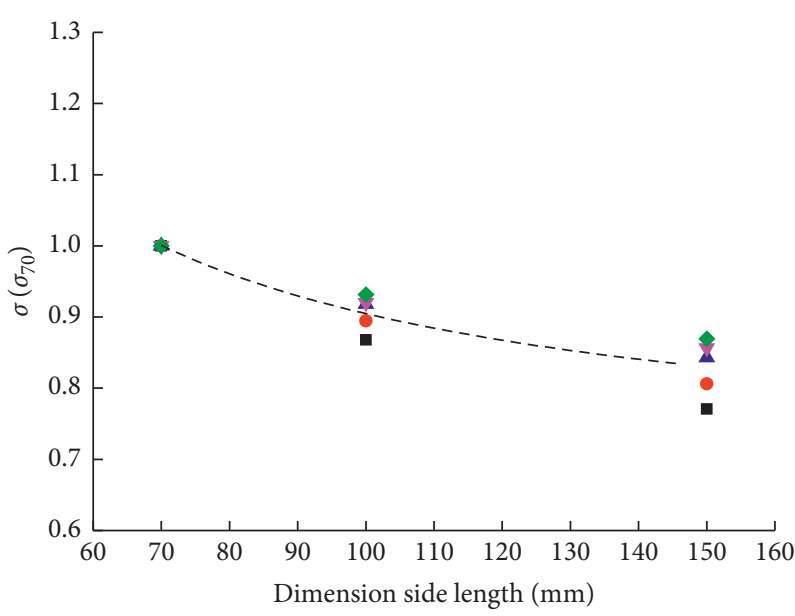

- Substitution rate $0 \%$

- Substitution rate $10 \%$

- Substitution rate $20 \%$ v Substitution rate $30 \%$

- Substitution rate $40 \%$

- - - Unified equation of size effect law

(b)

Figure 15: Rubber concrete equation of size effect law. (a) Size effect law equation and (b) unified equation of size effect law.

TABLE 4: Mathematical regression parameter values of the size effect law of rubber concrete.

\begin{tabular}{lccccc}
\hline \multirow{2}{*}{ Parameter values } & \multicolumn{5}{c}{ Rubber (\%) } \\
& 0 & 10 & 20 & 30 & 40 \\
\hline$\sigma_{\infty}$ & 16.99 & 13.34 & 12.06 & 8.72 & 8.30 \\
$D_{b}$ & 53.06 & 39.88 & 28.95 & 25.73 & 22.53 \\
$R^{2}$ & 0.99953 & 0.99913 & 0.99535 & 0.99987 & 0.99617 \\
\hline
\end{tabular}

by the size effect, while the concrete specimens with $40 \%$ rubber particles are the least affected by the size effect.

In order to examine the effect of rubber substitution rate on the parameters $\sigma_{\infty} / \sigma_{70}$ and $D_{b}$, we performed qualitative analysis on the basic mechanical properties of rubber concrete. It is found that when the rubber substitution rate is $\leq 20 \%$, the rubber concrete strength decreases significantly with the increase of the substitution rate, and when the rubber substitution rate is $>20 \%$, the rubber concrete compressive strength gradually decreases with the increase of the substitution rate. At the same time, when the specimen size is infinitely large and the rubber substitution rate approaches $100 \%$, the compressive strength will approach a strength value rather than 0 . On such basis, we propose that when the rubber substitution rate is $<20 \%$, both $\sigma_{\infty} / \sigma_{70}$ and $D_{b}$ have a linear relationship with the substitution rate; when the rubber substitution rate is $>20 \%$, both $\sigma_{\infty} / \sigma_{70}$ and $D_{b}$ tend to exhibit a power function relationship with the substitution rate. By performing mathematical regression analysis on the data in Tables 2 and 4, the expressions as shown in (8) (11) and the relationship as shown in Figure 16 were obtained.

When $0 \% \leq \xi \leq 20 \%$,

$$
\begin{gathered}
\frac{\sigma_{\infty}}{\sigma_{70}}=0.56814-0.00701 \times \xi, \quad R^{2}=0.99991, \\
D_{b}=52.685-1.2055 \times \xi, \quad R^{2}=0.99421 .
\end{gathered}
$$

When $\xi>20 \%$,

$$
\begin{aligned}
& \frac{\sigma_{\infty}}{\sigma_{70}}=0.5316 \times \xi^{0.09523}, \quad R^{2}=0.97054, \\
& D_{b}=83.27855 \times \xi^{-0.35076}, \quad R^{2}=0.96668 .
\end{aligned}
$$

In accordance with (8) (11) and Figure 16, the linear function relationship and power function relationship proposed for $\sigma_{\infty} / \sigma_{70}$ and $D_{b}$, respectively, in relation with rubber substitution rate have a high level of applicability. Thus by substituting (8) (11) into (7) successively, we obtained the nominal compressive strength prediction equations of the rubber concrete compressive strength size effect law under the coupling influence of size effect and rubber substitution rate, which are shown in (12) and (13). These equations have even a wider applicability, which is mainly manifested in two aspects: (1) the prediction equations for the compressive strength eigenvalue of rubber concrete were proposed by comprehensively considering the coupling of rubber substitution rate and size effect; compared with the equations proposed by literature [17-19], which only considered either the size effect or the content of rubber particles, (12) and (13) have a wider applicability. (2) The use of dimensionless expression provides a valuable reference for predicting the strength grade and the compressive strength of rubber concrete with other rubber substitution rates.

When $0 \% \leq \xi \leq 20 \%$, 


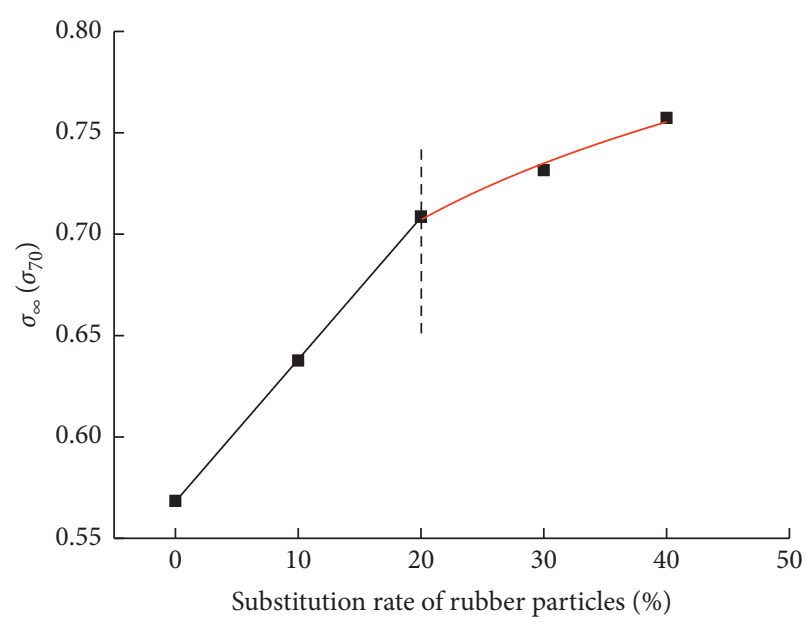

(a)

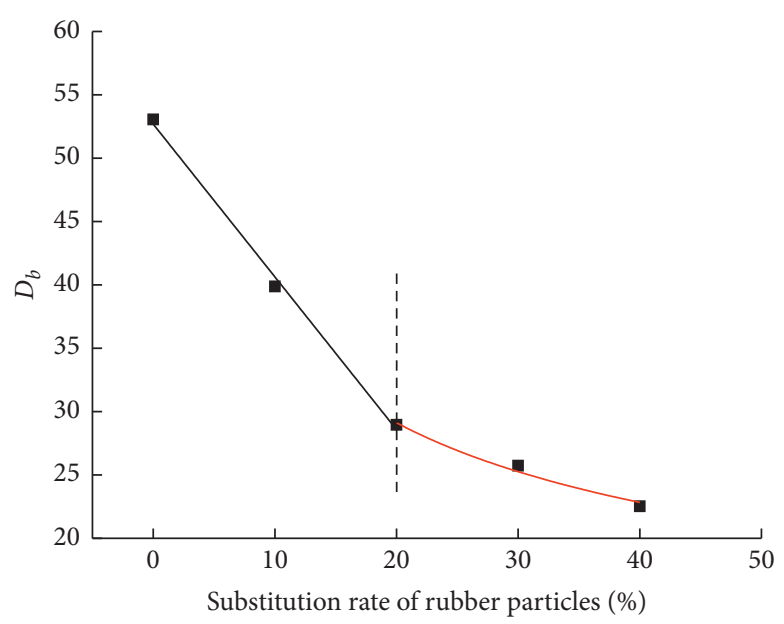

(b)

Figure 16: Relationship between the rubber substitution rate and the size effect law parameters. (a) $\sigma_{\infty} / \sigma_{70}$ eigenvalue of compressive strength. (b) $D_{b}$ structure size.

$$
\frac{\sigma_{N}}{\sigma_{70}}=(0.56814-0.00701 \times \xi) \times\left(1+\frac{52.685-1.2055 \times \xi}{D}\right)
$$

When $\xi>20 \%$,

$$
\frac{\sigma_{N}}{\sigma_{70}}=\left(0.5316 \times \xi^{0.09523}\right) \times\left(1+\frac{83.27855 \times \xi^{-0.35076}}{D}\right) \text {. }
$$

In accordance with (12) and (13), we derived the critical compressive strength eigenvalues for the rubber concrete with an infinitely big size corresponding to the substitution rate of $0 \%, 10 \%, 20 \%, 30 \%$, and $40 \%$, and the results are 16.60 MPa, 14.14 MPa, 11.67 MPa, 9.34 MPa, and 7.88 $\mathrm{MPa}$, respectively. Considering the applicable scope of the engineering size effect, when the nominal compressive strength differs from the critical strength eigenvalue by less than $5 \%$ (i.e., taking the specimen size corresponding to the nominal compressive strength as the critical size, when the rubber concrete size is greater than the critical size), the size effect on the rubber concrete strength can be ignored. In this paper, the critical size corresponding to the rubber substitution rate of $0 \%, 10 \%, 20 \%, 30 \%$, and $40 \%$ is equal to $1045 \mathrm{~mm}, 809 \mathrm{~mm}, 579 \mathrm{~mm}, 510 \mathrm{~mm}$, and $462 \mathrm{~mm}$, respectively. It can be seen that the critical size of rubber concrete gradually decreases as the rubber substitution rate increases.

\section{Conclusions}

An experimental study was carried out on the uniaxial compression, uniaxial splitting, pure shear, and compression size effect of rubber concrete with 5 different substitution rates by applying hydraulic servo and direct shear apparatus. Then, by deriving and comparing the failure modes and strength eigenvalues of rubber concrete specimens under different loading conditions, the following conclusions were drawn:

(1) The underlying mechanisms for the uniaxial compression, uniaxial splitting, and pure shear failure of rubber concrete with different substitution rates are basically the same and independent of the rubber substitution rate. The difference lies in that, with the increase of rubber substitution rate, the concrete specimens maintain a relatively good integrity under uniaxial compressive failure, while the failure sections under uniaxial slitting and pure shear gradually become uneven with an increasing amount of fallen rubber particles. Meanwhile, the increase of specimen size improves the integrity of the rubber concrete after failure.

(2) The development trends of force-deformation curves of the rubber concrete with different substitution rates under uniaxial compression, uniaxial splitting, and pure shear are basically the same. With the increase of rubber substitution rate, the compressive, splitting, and shear strength of concrete gradually decreases. On the contrary, the failure displacement of concrete under compression, splitting, and shear gradually increases, while the plastic deformation capacity of concrete significantly increases.

(3) For the basic mechanical properties of rubber concrete, the uniaxial compressive strength of concrete is most significantly affected by the rubber substitution rate. The compressive strength is reduced by a maximum of $60.67 \%$. The uniaxial splitting strength is affected by the rubber substitution rate by $58.38 \%$, while the shear strength is least affected by the rubber substitution rate, with a maximum reduction of $49.85 \%$. Meanwhile, by applying the existing compressive, splitting, and shear strength equations for ordinary concrete to analyze the strength relationships of rubber concrete, the results showed 
significant differences. We then analyzed the causes of such differences as well as the failure mechanisms in detail.

(4) For the same rubber substitution rate, it is found that the compressive strength of rubber concrete gradually decreases as the specimen side length increases, and the changing amplitude of the compressive strength influenced by the size effect gradually decreases as the rubber substitution rate increases. For the specimens of the same size, the compressive strength gradually decreases as the rubber substitution rate increases. When the rubber substitution rate is $>20 \%$, the decreasing amplitude of the compressive strength gradually decreases as the rubber substitution rate increases.

(5) We performed quantitative analysis on the compressive strength size effect of rubber concrete with different substitution rates from the perspectives of size effect ratio and size effect law and proposed the prediction equation for the relationship between the compressive strength of rubber concrete and the coupling of rubber substitution rate and size parameter, which shows a high level of applicability. On such basis, it is found that the critical size of rubber concrete gradually decreases as the rubber substitution rate increases.

\section{Data Availability}

The data used to support the findings of this study are available from the corresponding author upon request.

\section{Conflicts of Interest}

The authors declare that there are no conflicts of interest.

\section{Acknowledgments}

This work was supported by the National 12th Five Year Plan of Science and Technology Support Project of China (2015 BAL02b02), National Spark Plan Project of China (2015 GA690045), and Jiangsu Province "Six Talent Peaks" Team Project of China (XCL-CXTD-007).

\section{References}

[1] Z. Guo, Strength and Deformation of Concrete: Basis and Constitutive Relationship of Test, Tsinghua University Press, Beijing, China, 1997.

[2] O. Youssf, J. E. Elgawady, and X. Ma, "An experimental investigation of crumb rubber concrete confined by fibre reinforced polymer tubes," Construction and Building Materials, vol. 53, pp. 522-532, 2014.

[3] F. Jokar, G. M. Khorram, and N. Hataf, "Experimental investigation of mechanical properties of crumbed rubber concrete containing natural zeolite," Construction and Building Materials, vol. 208, pp. 651-658, 2019.

[4] H. A. Toutanji, "The use of rubber tire particles in concrete to replace mineral aggregates," Cement and Concrete Composites, vol. 18, no. 6, pp. 135-139, 1996.
[5] N. N. Eldin and A. B. Senouci, "Rubber-Tire particles as concrete aggregate," Journal of Materials in Civil Engineering, vol. 5, no. 4, pp. 478-496, 1993.

[6] K. A. Paine, R. K. Dhir, R. Moroney et al., "Use of crumb rubber to achieve freeze/thaw resisting concrete," Research in Immunology, vol. 143, no. 1, pp. 107-115, 2002.

[7] M. C. Bignozzi and F. Sandrolini, "Tyre rubber waste recycling in self-compacting concrete," Cement and Concrete Research, vol. 36, no. 4, pp. 735-739, 2006.

[8] I. B. Topçu, "The properties of rubberized concretes," Cement and Concrete Research, vol. 25, no. 2, pp. 304-310, 1995.

[9] G. Li, M. A. Stubblefield, G. Garrick, J. Eggers, C. Abadie, and B. Huang, "Development of waste tire modified concrete," Cement and Concrete Research, vol. 34, no. 12, pp. 2283-2289, 2004.

[10] E. Güneyisi, M. Gesoğlu, and T. Özturan, "Properties of rubberized concretes containing silica fume," Cement and Concrete Research, vol. 34, no. 12, pp. 2309-2317, 2004.

[11] H. E. M. Sallam, A. S. Sherbini, M. H. Seleem et al., "Impact resistance of rubberized concrete," Engineering Research Journal, vol. 31, no. 3, pp. 265-271, 2008.

[12] A. O. Atahan and A. Ö. Yücel, "Crumb rubber in concrete: static and dynamic evaluation," Construction and Building Materials, vol. 36, pp. 617-622, 2012.

[13] W. Tian, L. Zheng, and Y. Yuan, "Experimental study on brittleness of rubberized concrete," Concrete, vol. 11, no. 2, pp. 37-40, 2007.

[14] S. Chen, The Properties of Cement-Based Materials Containing Rubber, Southeast University, Jiangsu, China, 2005.

[15] R. Si, Q. S. Guo, and Q. Dai, "Durability performance of rubberized mortar and concrete with $\mathrm{NaOH}$-solution treated rubber particles," Construction and Building Materials, vol. 153, pp. 496-505, 2017.

[16] T. Gonen, "Freezing-thawing and impact resistance of concretes containing waste crumb rubbers," Construction and Building Materials, vol. 177, pp. 436-442, 2018.

[17] J. Liu, W. Yu, X. Du et al., "Meso-scale modelling of the size effect on dynamic compressive failure of concrete under different strain rates," International Journal of Impact Engineering, vol. 125, pp. 1-12, 2019.

[18] M. S. Meddah, S. Zitouni, and S. Belâabes, "Effect of content and particle size distribution of coarse aggregate on the compressive strength of concrete," Construction and Building Materials, vol. 24, no. 4, pp. 505-512, 2010.

[19] J. Su and F. Zhi, "Scale effect on cubic compressive strength of ordinary concrete and high-strength concrete," Journal of Building Materials, vol. 16, no. 6, pp. 1078-1081, 2013.

[20] Z. Yu, Q. Huang, X. Xie, and N. Xiao, "Experimental study and failure criterion analysis of plain concrete under combined compression-shear stress," Construction and Building Materials, vol. 179, pp. 198-206, 2018.

[21] N. M. Miller and F. M. Tehrani, "Mechanical properties of rubberized lightweight aggregate concrete," Construction and Building Materials, vol. 147, pp. 264-271, 2017.

[22] Z. P. Bazant, "Size effect," International Journal of Solids and Structures, vol. 37, no. 4, pp. 69-80, 2000. 